\title{
António Gomes
}

Instituto Superior de Engenharia do Porto

\section{Sistemas Automáticos de Detecção de Incêndio - Projecto e Execução}

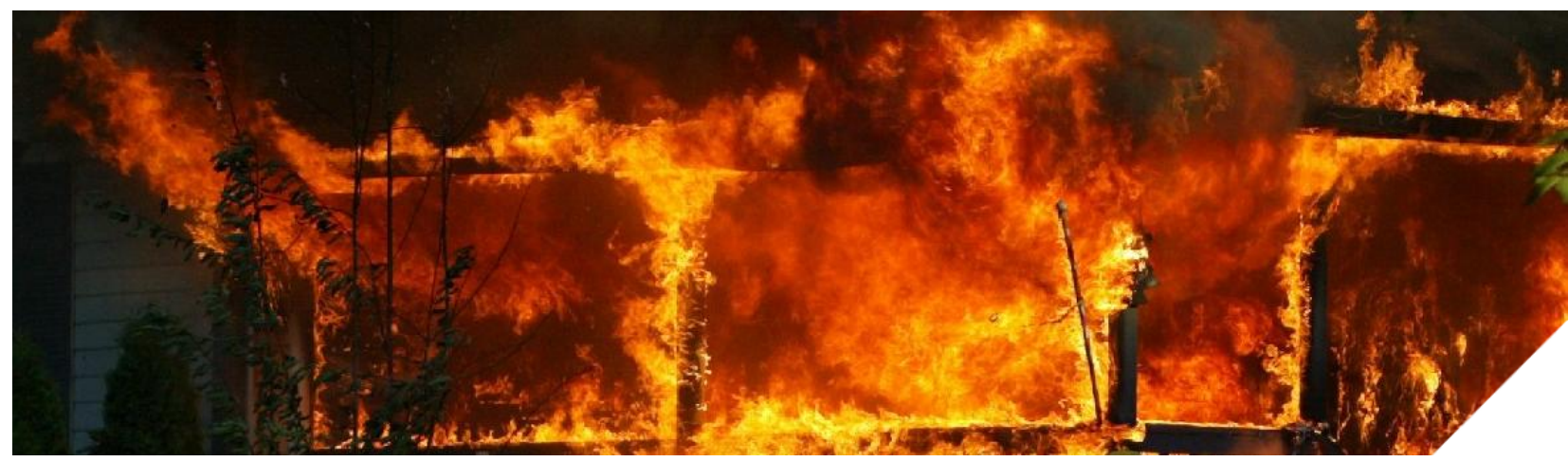

Enquadramento

Durante milhares de anos o fogo foi considerado um fenómeno da natureza, sendo olhado como um mistério, provocando medo, superstição e adoração.

O domínio do fogo por parte do homem permitiu a utilização do mesmo para aquecimento, cozinhar e mesmo para sua protecção.

Contudo, o fogo, grande elemento de evolução do homem, é também, em potencial, um dos seus maiores inimigos. Muitos são os fogos florestais e urbanos, que ocorrem diariamente, provocando mortes e avultados prejuízos materiais.

As causas principais dos incêndios são a deficiência nas canalizações eléctricas, a má utilização de equipamentos eléctricos, nomeadamente ferros, fogões, fornos e aquecedores eléctricos, bem como a negligência na utilização do fogo.

Os Sistemas Automáticos de Detecção de Incêndio (SADI) são hoje encarados como fazendo (quase) obrigatoriamente parte dos sistemas aplicados no sector da habitação, serviços, comércio e indústria.

A instalação de um SADI torna-se, assim, fundamental como elemento de garantia do bem-estar e da segurança das pessoas, velando pela sua salvaguarda e dos seus bens.

Um SADI é uma instalação técnica capaz de registar um princípio de incêndio, sem a intervenção humana, transmitir as informações correspondentes a uma central de sinalização e comando (CDI - central de detecção de incêndios), dar o alarme automaticamente, quer local e restrito, quer geral, quer à distância (alerta) e accionar todos os comandos (imediatos ou temporizados) necessários à segurança contra incêndios dos ocupantes e do edifício onde está instalado: fechar portas corta-fogo, parar elevadores, fechar registos corta-fogo, comandar sistemas automáticos de extinção de incêndios (SAEI), parar/ligar ventiladores, desligar energia eléctrica, etc.

Para que um SADI consiga cumprir de uma forma eficaz a sua missão é necessário que o projecto e a posterior execução das instalações sejam realizados em conformidade com os requisitos próprios da instalação.

O presente artigo pretende sistematizar a informação mais relevante no âmbito do projecto e execução das instalações de detecção automática de incêndio.

\section{Central de Sinalização e Comando}

Deve estar localizada de forma a que:

- As sinalizações e comandos estejam facilmente acessíveis ao pessoal responsável do edifício e aos bombeiros no caso de ser necessária a sua intervenção;

- O nível de ruído de fundo deve permitir a audição das indicações sonoras;

- O meio ambiente seja limpo e seco;

- O risco de danos mecânicos para o equipamento seja 


\section{ARTIGO TÉCNICO}

\section{António Gomes}

Instituto Superior de Engenharia do Porto

baixo;

- O risco de incêndio seja baixo e a zona protegida com pelo menos um detector, integrada no sistema;

- A iluminação ambiente permita que etiquetas e indicações visuais sejam facilmente visíveis e legíveis.

\section{Painéis Repetidores de Comando e de Sinalização}

São utilizados quando o edifício tiver mais do que uma entrada principal, quando houver possibilidade dos responsáveis pela segurança poderem estar longe da central e quando a distância entre a CDI e o elemento mais distante for considerável.

\section{Botões Manuais de Alarme}

Devem encontra-se claramente visíveis e identificáveis e ser posicionados de forma que possam ser fácil e rapidamente accionados por qualquer pessoa que detecte um princípio de incêndio.

Devem estar devidamente sinalizados e em locais em que não sejam ocultados por quaisquer elementos decorativos ou outros, nem por portas, quando abertas.

Devem ser posicionados em caminhos de evacuação, junto a cada porta de acesso a escadas de emergência (dentro ou fora) e em cada saída para o exterior e colocados junto a locais sujeitos a riscos especiais e junto dos extintores manuais.

Devem ser localizados de modo a que nenhuma pessoa dentro das instalações tenha que percorrer mais de $30 \mathrm{~m}$ para chegar a um botão.

Em locais em que os previsíveis utilizadores possam ser deficientes motores a distância deve ser reduzida.

Devem ser colocados entre 1,2 a 1,6m acima do chão, a uma altura recomendada de $1,5 \mathrm{~m}$.

\section{Sinalização do Alarme}

O método de transmitir o alarme aos ocupantes dos edifícios deve estar de acordo com os requisitos da estratégia da resposta a um alarme de incêndio.

Nalguns casos, os procedimentos de segurança podem requerer que o alarme seja dado inicialmente ao pessoal treinado que poderá tomar a seu cargo as operações subsequentes no edifício. Nesses casos não será necessário dar de imediato alarme geral de incêndio, deve, no entanto, deve ser providenciado um dispositivo que permita um alarme geral.

Qualquer alarme de incêndio, para ser reconhecido por pessoas não treinadas (como público em geral), deve ser dado, pelo menos, por meios audíveis que poderão ser dispositivos de alarme acústico ou sistemas de alarme por voz (tais como sistemas de chamada de pessoas).

Em zonas nas quais o sinal sonoro possa não ser eficaz, devido, por exemplo à existência de ruído de fundo excessivo, ocupantes com dificuldades auditivas, ou locais que obriguem a utilização de protecção auricular, deve ser usada sinalização óptica e/ou táctil como complemento da sinalização sonora.

\subsection{Sinais Sonoros}

Devem permitir a audição do sinal de alarme em qualquer local da instalação.

Os sinais sonoros de alarme devem ser inconfundíveis com qualquer outro sinal sonoro, ter um nível de som que seja imediatamente audível acima de qualquer ruído ambiente e audível em todos os locais do edifício ou recinto a que seja destinado.

O som utilizado para alarme de incêndio deverá ser contínuo e o mesmo em todas as partes do edifício. 


\section{ARTIGO TÉCNICO}

Instituto Superior de Enge

O número e tipo de equipamentos de alarme de incêndio usados devem ser suficientes para produzir o nível de som recomendado, devendo ser instaladas num edifício pelo menos duas sirenes, mesmo que o nível de som recomendado possa ser alcançado com uma única sirene.

Os equipamentos de alarme de incêndio, em geral devem, sempre que possível, ser instalados fora do alcance dos ocupantes e, no caso de se situarem a uma altura do pavimento inferior a $2,25 \mathrm{~m}$, ser protegidos por elementos que os resguardem de danos acidentais;

O som de alarme de incêndio deve ter um nível mínimo de $65 \mathrm{~dB}(\mathrm{~A})$, mas devendo ser sempre $5 \mathrm{~dB}(\mathrm{~A})$ superior a qualquer outro ruído que possa persistir por um período superior a 30 segundos.

\subsection{Dispositivos Visuais de Alarme de Incêndio}

Devem apenas ser usados como complemento dos alarmes sonoros, não devendo ser usados isoladamente, devendo qualquer dispositivo visual de alarme de incêndio deve ser claramente visível e distinto de quaisquer outros sinais visuais existentes nas instalações.

\section{Detectores Automáticos}

Os principais factores que condicionam a selecção do tipo de detector automático são:

- Requisitos legais;

- Materiais existentes no local e as manifestações da sua combustão;
- Configuração do local (particularmente o pé direito);

- Efeitos da ventilação e do aquecimento;

- Condições ambientais no interior dos compartimentos vigiados;

- Possibilidade de falsos alarmes.

Nenhum tipo de detector é mais adequado para qualquer situação, e a escolha final deverá depender das circunstâncias individuais, devendo os detectores seleccionados proporcionar mais rapidamente um aviso fiável nas condições ambientais dos locais em que serão instalados.

Embora existam no mercado, diversos tipos de detectores automáticos, os detectores de fumos e de temperatura, são os mais utilizados, permitindo dar resposta à quase totalidade das necessidades de detecção, assim, no presente trabalho apenas serão referidos estes dois tipos de detectores automáticos.

\subsection{Detectores de Fumos (Ópticos)}

São rápidos na detecção de um fogo e têm uma resposta suficientemente vasta para permitir uma utilização generalizada.

Responde a fumo visível, sendo bom para fogos onde não há chamas (fogos latentes), como é o caso de fogos com tecidos, mobília, móveis, etc.

São ideais para espaços amplos, onde a presença de fumo é mais facilmente detectada do que a elevação de

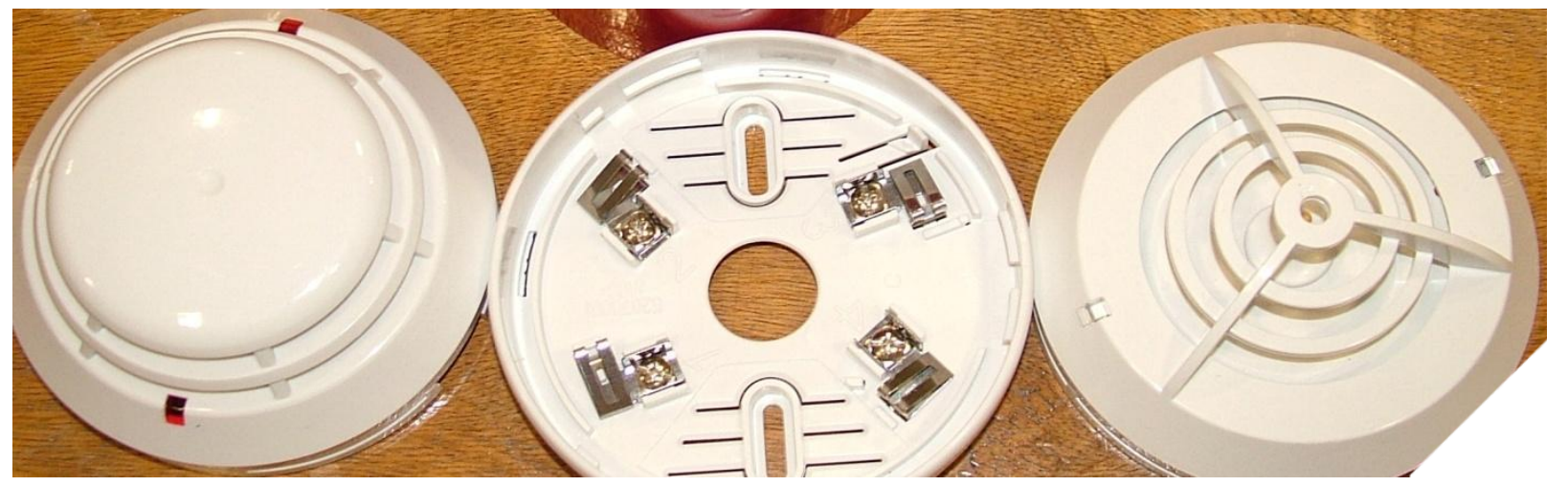




\section{ARTIGO TÉCNICO}

\section{António Gomes \\ Instituto Superior de Engenharia do Porto}

temperatura, pois o calor dissipa-se mais facilmente. Não são apropriados para locais onde se verifique a permanente existência de fumos, vapor ou pó, como é o caso de garagens, cozinhas e industrias transformadoras de madeiras, devido à possibilidade de ocorrência de falsos alarmes.

\subsection{Detector de Temperatura (Térmicos)}

São geralmente considerados como os menos sensíveis dos vários tipos de detectores disponíveis.

Os detectores termovelocimétricos são mais adequados em locais onde as temperaturas ambientes são baixas ou variam lentamente, enquanto que os detectores de temperatura fixa são mais adequados em locais onde se prevê que a temperatura ambiente possa variar rapidamente em curtos espaços de tempo.

Regra geral, os detectores de temperatura têm uma maior resistência a condições ambientais adversas do que outros tipos de detectores.

São apropriados para locais:

- $\quad$ De humidade do ar $\geq 95 \%$;

- Onde se preveja que o incêndio não liberte fumo;

- Onde exista forte risco de engorduramento;

- Onde se possam desenrolar trabalhos que libertem fumo ou vapor;

- Cozinhas;

- Aquecedores com combustíveis sólidos;

- Pequenas garagens para estacionamento de veículos de motor de combustão.

Não são apropriados para locais:

- Com altura $>7,5 \mathrm{~m}$;

- Onde se prevejam fogos lentos e encobertos;

- Onde, face aos riscos, a detecção precoce é necessária.

\subsection{Localização e Distribuição}

Os detectores automáticos devem ser posicionados de forma que os produtos resultantes de qualquer incêndio dentro da área protegida possam chegar aos detectores sem grande dissipação, atenuação ou demora.

As características específicas das instalações, requerem particular atenção aquando do projecto e da execução das instalações, sob pena de os sistemas previstos não garantirem a completa e eficaz protecção dessas mesmas instalações.

Assim, e relativamente à utilização de detectores automáticos térmicos e de fumo, será necessário atender às seguintes considerações:

\section{a) Detectores em Tectos Planos}

Na generalidade o desempenho de detectores térmicos ou de fumo depende da existência de um tecto fechado por cima dos detectores.

Os detectores devem ser colocados de modo a que os seus elementos sensitivos se situem nos $5 \%$ superiores do pé direito dos espaços.

Para prevenir a possível existência de uma camada envolvente fria, os detectores não devem ser embebidos no tecto.

A tabela 1 , indica os limites de altura dos tectos e o raio de acção, para detectores instalados na zona dos $5 \%$ superiores.

\section{b) Detectores em Tectos Inclinados}

Para detectores instalados em tectos inclinados, o raio indicado na tabela 1 pode ser aumentado em $1 \%$ por cada $1^{\circ}$ de inclinação do tecto, até um aumento máximo de $25 \%$. 


\section{ARTIGO TÉCNICO}

Instituto Superior de Engenharia do Porto

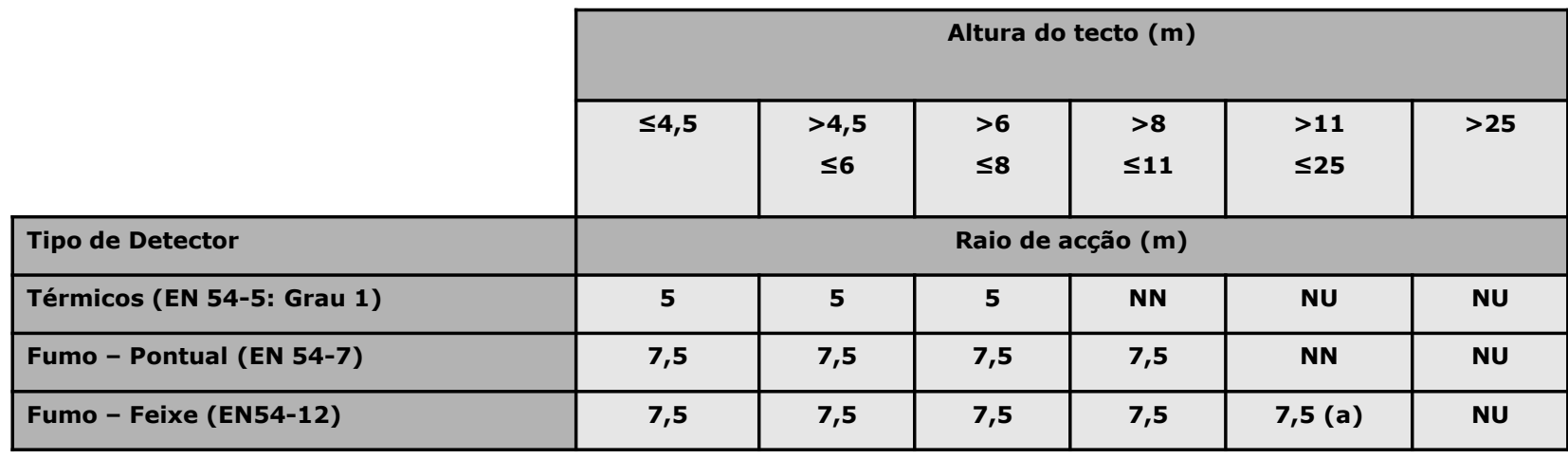

NU - Não utilizável para esta gama de alturas.

NN - Normalmente não utilizável, mas pode ser utilizado em aplicações especiais.

a) Será normalmente necessária uma segunda camada de detectores a aproximadamente metade da altura do tecto.

Tabela 1 - Limites de altura dos tectos e raio de acção

Em tectos curvos a inclinação deve ser obtida através da média da inclinação total em toda a área.

No caso do espaço protegido ter um tecto em escada os detectores devem ser instalados em cada um dos vértices.

No caso da diferença de altura entre o cimo e a base de cada vértice ser inferior a $5 \%$ da altura total do vértice acima do chão, a sala deve ter o tratamento de uma sala de tecto plano.

\section{c) Paredes, Divisórias e Obstáculos}

Os detectores (excepto os detectores ópticos de feixe) não devem ser instalados a menos de $0,5 \mathrm{~m}$ de qualquer parede ou divisória.

No caso do espaço ter menos de 1,2 m, o detector deve ser instalado no terço do meio.

Quando as salas estão divididas em secções por paredes, divisórias ou estantes de armazenagem que fiquem a uma distância inferior a 0,3 m do tecto, as divisórias devem ser consideradas tal como se chegassem ao tecto e as secções devem ser consideradas como salas diferentes.

Deve existir um espaço desobstruído mínimo de 0,5 m à volta de cada detector.

\section{d) Irregularidades do Tecto}

Os tectos que tenham irregularidades com alturas inferiores a $5 \%$ do pé direito devem ser tratados como se fossem lisos e devem ser aplicados os seguintes limites radiais, constantes da tabela 1 .

Qualquer irregularidade do tecto (tal como uma viga) com uma altura superior a $5 \%$ do pé direito deve ser tratada como uma parede e devem ser aplicados os seguintes requisitos:

- $\quad \mathrm{D}>0,25 \times(\mathrm{H}-\mathrm{h}) \Rightarrow$ Um detector em todas as células;

- $\quad \mathrm{D}<0,25 \times(\mathrm{H}-\mathrm{h}) \Rightarrow$ Um detector em células alternadas;

- $\quad \mathrm{D}<0,13 \times(\mathrm{H}-\mathrm{h}) \Rightarrow$ Um detector em cada três células.

Em que:

$D$ - Distância entre vigas (m), medida fora a fora;

$\mathrm{H}$ - Pé direito da sala;

$\mathrm{h}$ - Altura da viga.

Se a disposição do tecto for de modo a formar séries de pequenas células (como num favo de mel), então, dentro dos limites radiais da Tabela 1 , um único detector pode cobrir um grupo de células.

O volume interno das células cobertas por um só detector não deve exceder: 


\section{ARTIGO TÉCNICO}

\section{António Gomes \\ Instituto Superior de Engenharia do Porto}

- Detectores Temperatura: $V=6 \mathrm{~m}^{2} \times(\mathrm{H}-\mathrm{h})$

- Detectores Fumo: $V=12 \mathrm{~m}^{2} \times(\mathrm{H}-\mathrm{h})$

\section{e) Detecção Acima de Tectos Falsos}

Quando uma sala tem um tecto falso perfurado, a colocação dos detectores deve ter em consideração dois objectivos:

- Protecção contra fogos que comecem abaixo do tecto falso;

- Protecção contra fogos que comecem acima do tecto falso.

No caso das perfurações do tecto falso serem pequenas, e não exista ventilação pressurizada que empurre o fumo através deste, a protecção contra fogos que comecem abaixo do tecto falso requer a colocação de detectores abaixo do tecto falso.

Caso não exista qualquer risco do fogo começar abaixo do tecto falso, os detectores devem ser colocados acima deste.

No caso das perfurações perfazerem mais do que $40 \%$ em qualquer secção de $1 \mathrm{~m} \times 1 \mathrm{~m}$ do tecto, as dimensões de cada orifício excederem $10 \mathrm{~mm} \times 10 \mathrm{~mm}$, e a espessura do tecto não exceder três vezes a dimensão mínima de uma furação, os detectores acima do tecto falso podem ser utilizados para detectar um fogo que comece abaixo do tecto falso, e podem ser dispensados detectores abaixo deste.

\section{f) Detecção Abaixo do Chão Falso}

Quando as salas têm chão falso, devem ser instalados detectores por baixo do chão tal como se o vazio abaixo do chão falso fosse outro compartimento.

Dispensa-se a colocação de detectores por baixo do chão falso, quando se verificar, pelo menos, uma das seguintes condições:

- o chão falso seja perfurado;

- o chão falso seja de um material que tenha uma reacção ao fogo classificada como A1, A2 ou B1 (Anexos II e III do
RG-SCIE) e não exista carga térmica debaixo.

\section{g) Detectores que não estejam debaixo de tecto}

$\mathrm{Na}$ ausência de um tecto ou de um plano estratificado, os produtos da combustão confinam-se à coluna ascendente acima do fogo.

Caso se utilizem detectores de fumo ou calor para detectar os produtos da combustão na coluna ascendente (tal como quando são utilizados nos átrios detectores de feixe em níveis baixos, ou quando são utilizados detectores sem tecto), os limites em altura para a operação são os indicados na Tabela 1, e o raio de operação efectivo (tanto para detectores de fumo como de calor) deve ser calculado como sendo $12,5 \%$ da altura medida do previsível foco de incêndio que esteja mais alto até ao detector acima.

Cada sala protegida ou espaço fechado deve conter no mínimo um detector.

\section{Comandos}

A sinalização do alarme deve ser usada também para accionar, equipamentos auxiliares, tais como:

- Equipamento de extinção;

- Portas corta-fogo;

- Sistemas de controlo de fumo;

- Registos corta-fogo;

- Paragem de ventilação;

- Controlo de elevadores;

- Portas de segurança.

\section{Canalizações}

As canalizações devem satisfazer quaisquer requisitos especificados pelo fabricante ou fornecedor do equipamento, devendo ser dada particular atenção à capacidade condutora e à atenuação do sinal.

Devem ser respeitadas as recomendações existentes em regulamentos nacionais relativamente a tipos de cabo e sua instalação. 


\section{ARTIGO TÉCNICO}

\section{António Gomes \\ Instituto Superior de Engenharia do Porto}

\section{8) Conclusão}

Este artigo visou abordar aspectos técnicos e conceptuais, ao nível do projecto e da instalação de Sistemas Automáticos de Detecção de Incêndios pretendendo e, fundamentalmente, contribuir para o enriquecimento do conhecimento das competências no âmbito de actuação do projecto de segurança.

\section{Fontes de Informação Relevantes}

Segurança Contra Incêndio em Edílicos, NT12: Nota Técnica Complementar do RG-SCIE / Refa VII.III.01, Sistemas Automáticos de Detecção de Incêndio, Autoridade Nacional de Protecção Civil, 2007

Regulamento Geral de Segurança Contra Incêndio em Edílicos, Autoridade Nacional de Protecção Civil, Versão aprovada na Generalidade na RCM, 25 de Janeiro de 2007

EN54 - Sistemas de detecção e de alarme de incêndio -

Parte3-4-5-7-11-12-20

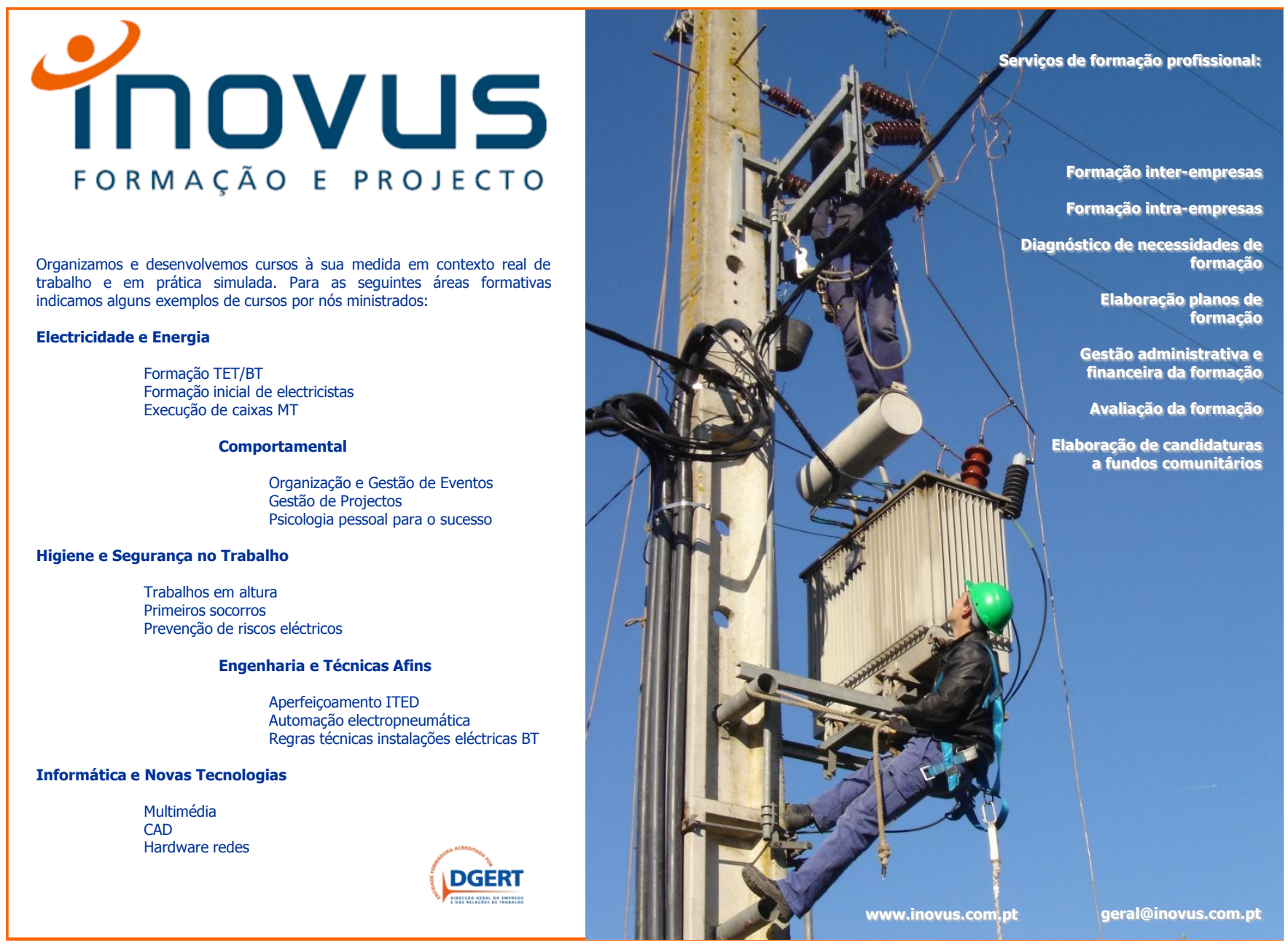

